\title{
Period-homologous sequence polymorphisms in subterranean mammals of the Spalax ehrenbergi superspecies in Israel
}

\author{
R. BEN-SHLOMO, H.-S. SHIN*† \& E. NEVO \\ Institute of Evolution, University of Haifa, Haifa, 31905, Israel and *Whitehead Institute for Biomedical Research and \\ Department of Biology, MIT, Nine Cambridge Center, Cambridge, MA 02142, U.S.A
}

\begin{abstract}
Restriction fragment length polymorphism (RFLPs) of the mouse period-homologous sequence were studied in 13 populations of the four chromosomal species $(2 n=52,54,58$ and 60$)$ of the mole rat, Spalax ehrenbergi superspecies in Israel. The period locus of Drosophila melanogaster is implicated in controlling the circadian rhythm as well as the male courtship song rhythm. Multiple DNA homologies exist in the mole rat and correspond to more than 10 loci. The level of polymorphism is very high, with a large number of alleles per locus, increasing from the northern to the southern species along a gradient of increasing aridity. Variation was also found in an isolated desert population, with a unique fragment specific to this population. Fragment variation allows distinction between chromosomal species, and confirms earlier evidence that gene flow does not occur between them. A correlation was found between some allelic fragments and the number of apparent harmonics of the courtship calls. This finding suggests an interesting testable hypothesis that the existence of a locus (homology) is responsible for the courtship call parameters.
\end{abstract}

Keywords: mole rat, Per-homologous sequence, RFLP.

\section{Introduction}

Daily rhythms in many behavioural, physiological and biochemical functions are generated by endogenous oscillators which function as internal 24-h clocks. Under natural conditions these oscillators are synchronized to the daily environmental cycle of light and darkness (reviewed in Takahashi \& Zatz, 1982). Circadian rhythms are genetically determined (Hall, 1990). Mutations which alter the expression of rhythmicity have been described in Drosophila melanogaster, D. pseudoobscura, Neurospora crassa, and Chlamydomonas reinhardi (reviewed in Feldman, 1982), and in hamsters (Ralph \& Menaker, 1988), mice (Schwartz \& Zimmerman, 1990) and the Brattleboro rat (Reppert et al., 1987). In many cases, the mutants also show alterations to other time-dependent properties, such as their response to light and temperature.

Correspondence: Rachel Ben-Shlomo, Institute of Evolution, University of Haifa, Haifa, 31905, Israel.

†Present address: Dr H.-S. Shin, Department of Life Science, Pohang Institute of Science and Technology, Mt. 31, Hyoja-Dong, Pohang, Kyungbuk, 790-330, Republic of Korea.
The period (per) locus of Drosophila melanogaster is one of the best studied behavioural genes in any species. The gene is implicated in the control of both the circadian and male courtship song rhythms (Konopka \& Benzer, 1971; Kyriacou \& Hall, 1980). The per gene product is involved in the control of two very different neural oscillators: one in the brain controlling circadian rhythmicity and the second in the thoracic ganglia, which controls courtship song rhythmicity (Hall, 1984).

The structure of some segments of the predicted protein consists of uninterrupted tandem repetitions of the sequence ACNGGN. These tandem repeats code for poly-threonine-glycine ( $\mathrm{Thr}-\mathrm{Gly}$ ) tracts which are up to 48 amino acids long (Shin et al., 1985; Jackson et al., 1986; Reddy et al., 1986). In addition, a region beginning about $100 \mathrm{bp}$ upstream from the Thr-Gly repeat is rich in serine-glycine (Ser-Gly) codons. Immunological and biochemical studies of the per protein indicate that it may have some proteoglycanlike qualities (Reddy et al., 1986; Hall, 1990). Typically, proteoglycans are found to be associated with the cell surface, or in extracellular locations (Edmunds, 1988). 
Hybridization of the Drosophila per locus probe with genomic DNA can detect homologies among chickens, mice and humans (Shin et al., 1985). The discovery of these homologies, as well as the immunological implications that the per protein has some proteoglycan qualities, both point to a possible role that this unusual protein segment may play. Such a segment composed of alternating Thr-Gly and Ser-Gly residues contributes to the organization of biological rhythms, including courtship songs in many species, and as a result, to mate selection (Yu et al., 1987).

We tested the hybridization homologies and the restriction fragment length polymorphisms (RFLPs) of the mouse per-homologous sequence in the complex of four chromosomal species $(2 n=52,54,58$ and 60$)$ of the actively speciating blind subterranean mole rat, Spalax ehrenbergi, in Israel (overviewed in Nevo, 1991). This evolutionary model of the superspecies in Israel provides a unique potential test of both the perhomologous sequence function in rhythmicity and in mating calls in mammals. S. ehrenbergi is totally blind, but the animals do perceive photoperiodic changes (Haim et al., 1983; Pevet et al., 1984; Nevo, 1989). The chromosomal species differ in both levels and patterns of activity (Nevo et al., 1982). Likewise, in the S. ehrenbergi superspecies, species-specific 'courtship' calls provide a major premating isolating mechanism in speciation (Nevo et al., 1987).

The objective of the present research was to: (a) examine the pattern of homologies of the per sequence in Spalax; (b) compare the RFLPs of these homologies among and within the four chromosomal species; and (c) assess whether this per-homologous sequence is associated with periodic rhythms, or with courtship call rhythms, as a mechanism of reproductive isolation.

\section{Materials and methods}

\section{Sampling}

We tested DNA polymorphisms of the per-like genes in 121 mole rats, comprising 13 populations and four chromosomal species of the Spalax ehrenbergi superspecies in Israel (Table 1 and Fig. 1). Live animals were brought to the laboratory, killed and dissected. Tissues were instantly frozen in liquid nitrogen and then stored at $-80^{\circ} \mathrm{C}$.

\section{DNA extraction, digestion and blotting}

High molecular weight genomic DNA was extracted from the kidneys, following Holland (1983). Two different six-base recognition endonucleases (BamHI and $E c o R I$ ), and one four-base recognition enzyme $(T a q \mathrm{I})$, were used for digestion. Twenty-five micrograms of genomic DNA were incubated overnight with 150 units of a given endonuclease, following the conditions recommended by the supplier (New England, BioLabs, U.S.A.). Fully digested DNA was precipitated in ethanol, followed by electrophoresis through both

Table 1 Tested populations of Spalax ehrenbergi

\begin{tabular}{lclcl}
\hline $\begin{array}{l}\text { Chromosomal } \\
\text { species }\end{array}$ & Number* & Location & $\begin{array}{l}\text { Number of } \\
\text { animals }\end{array}$ & $\begin{array}{l}\text { Type of } \\
\text { population }\end{array}$ \\
\hline $2 n=52$ & 1 & Maalot & 9 & NHZ \\
& 2 & Kerem Ben Zimra & 10 & Central \\
$2 n=54$ & 3 & Qiryat Shemona & 10 & Marginal \\
& 4 & Hermon & 10 & Marginal \\
& 5 & Quneitra & 10 & Central \\
$2 n=58$ & 6 & El-Al & 9 & NHZ \\
& 7 & Kabri & 10 & NHZ \\
& 8 & Zippori & 10 & Central \\
$2 n=60$ & 9 & Afiq & 9 & NHZ and \\
& 10 & Anza & 10 & marginal \\
& 11 & Jerusalem & 11 & Marginal \\
& 12 & Lahav & 9 & Central \\
& 13 & Sede Boqer & 4 & Desert isolate \\
Total & & & 121 & \\
\hline
\end{tabular}

*Localities listed as in Fig. 1.

$\mathrm{NHZ}=$ near hybrid zone. 


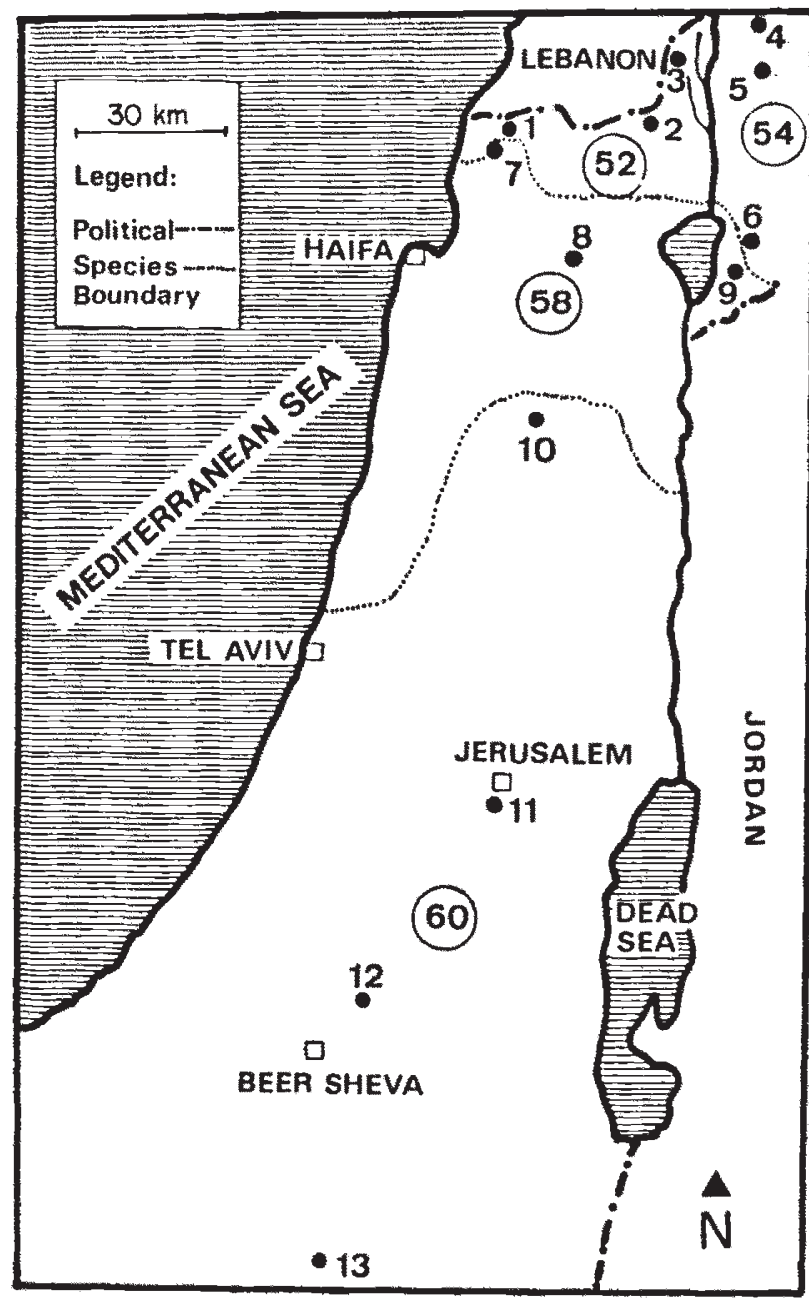

Fig. 1 Geographical distribution of the chromosomal species and the tested population of the Spalax ehrenbergi superspecies in Israel.

0.6 and 1.0 per cent agarose gels for $16 \mathrm{~h}$ at $30 \mathrm{~V}$. The DNA was denatured and transferred to nylon filters (Hybond-N, Amersham, U.K.) following Southern (1975).

\section{Hybridization}

The probe used was a $2.5 \mathrm{~kb}$ EcoRI insert from a mouse cosmid, homologous to the Drosophila per sequence, containing a conceptual translation of a 2.1$\mathrm{kb}$ open-reading frame. The translational frame was composed of two hexamer repeats, ACNGGN (Thr-Gly) and TACGGC (Ser-Gly) (Shin et al., 1985). The DNA insert was radiolabelled by the random prime method of Feinberg \& Voglestein (1984) (Amersham: 'Multiprime DNA labelling systems') overnight at room temperture. Hybridization of ${ }^{32} \mathrm{P}$-labelled probes with the DNA on the filters was performed in the 50 per cent formamide solution overnight at $42^{\circ} \mathrm{C}$, following the filter manufacturer's (Amersham, U.K.) recommended methods. Filters were washed under high-stringency conditions of $0.1 \times \mathrm{SSPE}$ at $64^{\circ} \mathrm{C}$ and were autoradiographed at $-70^{\circ} \mathrm{C}$ using two intensifying screens (Kodak rapid or super rapid).

\section{Data analysis}

The data were analysed as fragment and/or fragment combination frequencies by scoring the bands directly from the autoradiograph.

Genetic indices of hypervariable regions were estimated following Jeffreys et al. (1985) and Georges et al. (1988). The indices are: $q$ - the mean population frequency of a resolvable allele, assuming that comigrating bands are always the same allele; $x$ - the mean probability that a fragment present in one individual is also present in another one taken randomly from the population:

$x=q^{2}+2 q(1-q)=2 q-q^{2} ;$

and $h$ - the mean probability for a resolvable fragment to be present in a heterozygous state:

$h=2 q(1-q) /\left(2 q-q^{2}\right)=2(1-q) /(2-q)$.

\section{Results}

\section{Digestion of Spalax DNA with BamHI}

Hybridization of Spalax DNA digested with BamHI with the mouse per-homologous sequence yielded many bands (more than 15). All the strong hybridization bands were polymorphic (Fig. 2a). The distribution of the different fragments and their sizes appears in Table 2, and the frequency of the different fragment combinations appears in Table 3.

The chromosomal species vary in their per RFLPs. The $2 n=54$ species was monomorphic for fragments $1-7$. The chromosomal species $2 n=52$ was polymorphic, whereby the main combination of fragments was either $1-7$ or $1-7-8$. In the $2 n=58$ species, population 9 (Afiq), located near $2 n=54$ in the Golan Heights (Fig. 1), was polymorphic, but had the same predominant fragment combination as that of $2 n=54$. The two other populations of $2 n=58$ were entirely different. Population 8 (Zippori) was monomorphic for fragment 3 , and population 7 (Kabri) was polymorphic with mainly two fragments, 3 and 4, sharing fragment 3 with the Kabri (7) population, and fragment 4 with the Golan Heights, Afiq (9) population. Thus, the species shared fragments although the differentiation between the populations was remarkable. The species $2 n=60$ 
(a) $B a m \mathrm{HI}$

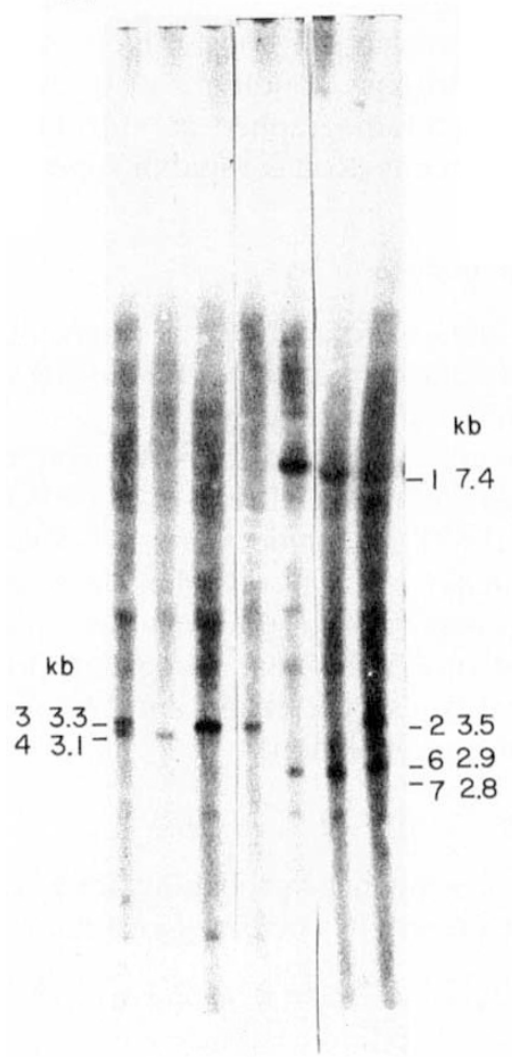

(b) EcoRI

(c) TaqI

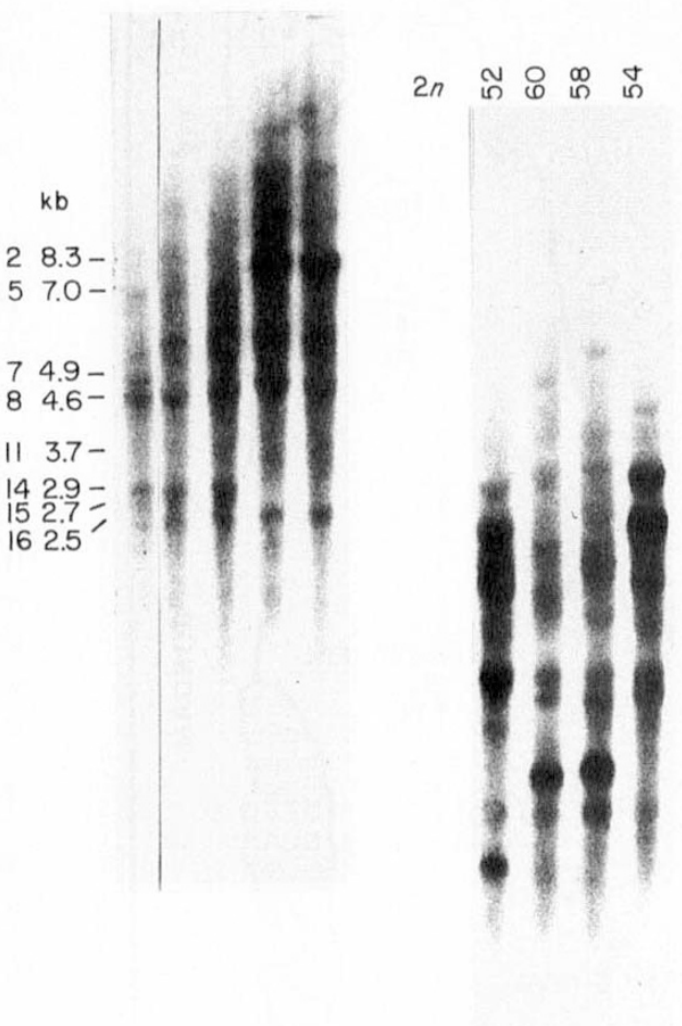

Fig. 2 Fragment polymorphism of per-homologous sequences resulting from digestion with (a) BamHI, (b) EcoRI, (c) TaqI.

Table 2 Frequency and distribution of Per-homologous sequence fragments in the four chromosomal species of Spalax ehrenbergi

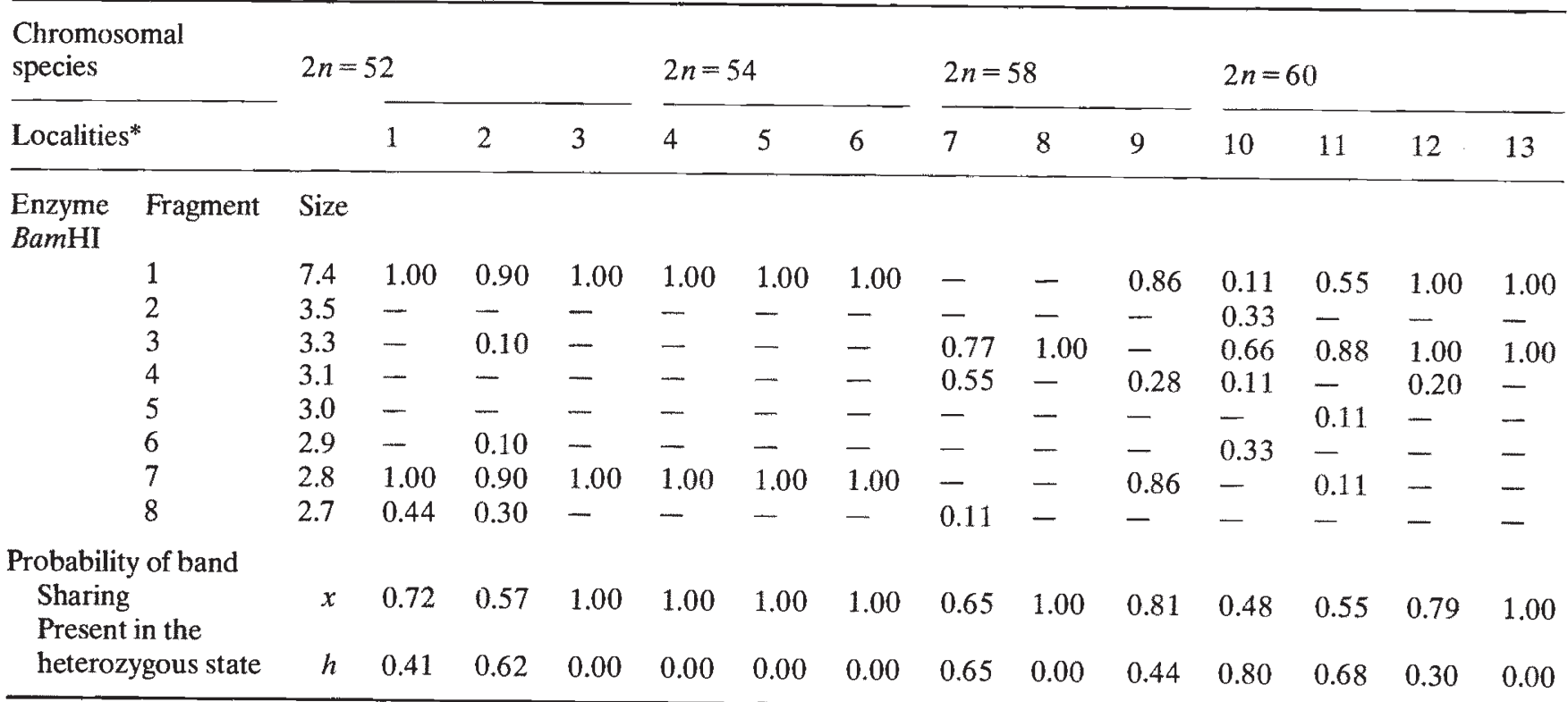

*Localities as in Fig. 1 and Table 1.

Fragment sizes are measured in kilobases. 
Table 3 Frequency and distribution of per-homologous sequence fragments combinations in the four chromosomal species of Spalax ehrenbergi

\begin{tabular}{|c|c|c|c|c|c|c|c|c|c|c|c|c|c|c|}
\hline \multirow{2}{*}{\multicolumn{2}{|c|}{$\frac{\text { Chromosomal species }}{\text { Localities* }^{*}}$}} & \multicolumn{3}{|c|}{$2 n=52$} & \multicolumn{3}{|c|}{$2 n=54$} & \multicolumn{3}{|c|}{$2 n=58$} & \multicolumn{4}{|c|}{$2 n=60$} \\
\hline & & 1 & 2 & 3 & 4 & 5 & 6 & 7 & 8 & 9 & 10 & 11 & 12 & 13 \\
\hline \multicolumn{15}{|c|}{ Enzyme fragment combinations } \\
\hline \multirow{16}{*}{ BamHI } & $1-3$ & - & - & - & - & - & - & - & - & - & - & 0.44 & 0.80 & 1.00 \\
\hline & $1-7$ & 0.44 & 0.60 & 0.70 & 1.00 & 1.00 & 1.00 & - & - & 0.72 & - & 0.11 & - & - \\
\hline & $1-7-8$ & 0.44 & 0.30 & 0.30 & - & - & - & - & - & - & - & - & - & - \\
\hline & 3 & - & - & - & - & - & - & 0.33 & 1.00 & - & 0.44 & 0.33 & - & - \\
\hline & 4 & - & - & - & - & - & - & 0.22 & - & 0.14 & - & - & - & - \\
\hline & $3-4$ & - & - & - & - & - & - & 0.33 & - & - & - & - & - & - \\
\hline & $1-3-4$ & - & - & - & - & - & - & - & - & - & 0.11 & - & 0.20 & - \\
\hline & $1-3-7$ & 0.11 & - & - & - & - & - & - & - & - & - & - & - & - \\
\hline & $1-4-7$ & - & - & - & - & - & - & - & - & 0.14 & - & - & - & - \\
\hline & 2 & - & - & - & - & - & - & - & - & - & 0.11 & - & - & - \\
\hline & $2-6$ & - & - & - & - & - & - & - & - & - & 0.11 & - & - & - \\
\hline & $2-3-6$ & - & - & - & - & - & - & - & - & - & 0.11 & - & - & - \\
\hline & 6 & - & - & - & - & - & - & - & - & - & 0.11 & - & - & - \\
\hline & $3-6 \dagger$ & - & 0.10 & - & - & - & - & - & - & - & - & - & - & - \\
\hline & $3-5$ & - & - & - & - & - & - & - & - & - & - & 0.11 & - & - \\
\hline & $3-8 \dagger$ & - & - & - & - & - & - & 0.11 & - & - & - & - & - & - \\
\hline \multicolumn{2}{|c|}{ Number of combinations } & 3 & 3 & 2 & 1 & 1 & 1 & 4 & 1 & 3 & 6 & 4 & 2 & 1 \\
\hline
\end{tabular}

*Localities as in Fig. 1 and Table 1.

$\dagger$ Due to very small differences in size it was impossible to determine whether two rare fragments were identical or only similar in size.

showed greater polymorphism than the other three species. It shared fragment 3 with the populations of $2 n=58$ and showed a clinal increase southward in the combination of fragments $1-3$, which reached fixation in the Sede Boqer desert isolate. The frequency of the 1-3 'allele' among populations $10-13$ was very strongly correlated with decreasing latitude (latitude range: $30.87-32.35 ; r^{2}=0.9765, P=0.0118$ ).

Deciphering the underlying genetic basis of the BamHI polymorphism was difficult owing to the multiple homologies. However, the common fragments were distributed as a minimum of one fragment, and a maximum of three per individual. This suggests that BamHI polymorphism involves only one gene, which apparently has a $B a m \mathrm{HI}$ recognition site inside the probe region, yielding two fragments. One of the fragments might be no. 1 and the other might be either 7 or 3 (Fig. 3). The appearance of fragment 3 alone may have been the result of a mutation which caused an additional restriction site in fragment 1 , shortening and possibly excluding it from the gel. Fragment 4 is probably allelic to fragment 3 , but it could be allelic to $1+3$ as well. Further study is required to determine decisively the different alleles and genetics of the BamHI polymorphism in Spalax.

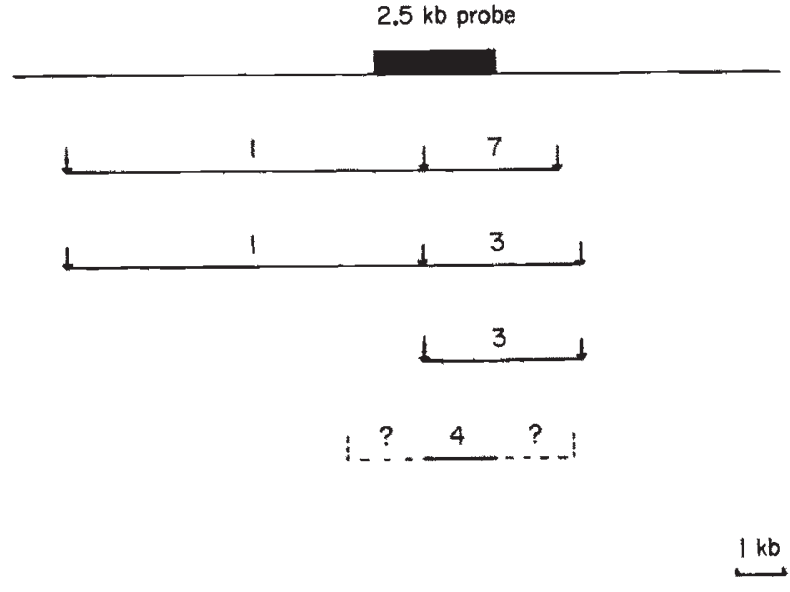

Fig. 3 A possible restriction map of per-homologous sequence hybridizing to Spalax DNA digested with BamHI.

\section{EcoRl polymorphism}

Per-EcoRI polymorphism yielded at least 16 bands, ranging in size from 9.0 to $2.5 \mathrm{~kb}$ (Fig. $2 \mathrm{~b}$ and Table 4 ). All the bands were polymorphic. Some of the fragments were rare and appeared only in one or two individuals. Ten fragments were common in at least some 
Table 4 Frequency and distribution of per-homologous sequence fragments in the four chromosomal species of Spalax ehrenbergi

\begin{tabular}{|c|c|c|c|c|c|c|c|c|c|c|c|c|c|c|c|}
\hline \multirow{2}{*}{\multicolumn{2}{|c|}{$\frac{\text { Chromosomal species }}{\text { Localities* }^{*}}$}} & & \multicolumn{3}{|c|}{$2 n=52$} & \multicolumn{3}{|c|}{$2 n=54$} & \multicolumn{3}{|c|}{$2 n=58$} & \multicolumn{4}{|c|}{$2 n=60$} \\
\hline & & & 1 & 2 & 3 & 4 & 5 & 6 & 7 & 8 & 9 & 10 & 11 & 12 & 13 \\
\hline \multirow{17}{*}{$\begin{array}{l}\text { Enzyme } \\
\text { EcoRI }\end{array}$} & Fragment & Size & & & & & & & & & & & & & \\
\hline & 1 & 9.0 & - & - & - & 0.14 & - & - & - & - & - & - & - & - & - \\
\hline & 2 & 8.3 & 1.00 & 1.00 & 1.00 & 1.00 & 1.00 & 1.00 & - & - & 0.75 & 0.83 & 0.38 & 0.86 & 1.00 \\
\hline & 3 & 7.7 & - & - & - & - & - & - & - & - & 0.25 & 0.33 & 0.63 & 0.14 & - \\
\hline & 4 & 7.5 & - & - & - & - & - & - & - & 0.17 & - & - & - & - & - \\
\hline & 5 & 7.0 & - & - & - & - & - & - & 1.00 & 1.00 & 0.13 & - & - & - & - \\
\hline & 6 & 6.6 & - & 0.10 & - & - & - & - & - & - & - & - & - & - & - \\
\hline & 7 & 4.9 & - & - & - & - & - & - & 0.13 & - & 0.13 & - & - & - & - \\
\hline & 8 & 4.6 & 1.00 & 1.00 & 1.00 & 1.00 & 1.00 & 1.00 & 1.00 & 1.00 & 0.88 & 1.00 & 0.90 & 0.67 & 1.00 \\
\hline & 9 & 4.4 & - & - & - & - & - & - & - & - & - & - & 0.10 & - & - \\
\hline & 10 & 4.2 & - & 0.10 & - & - & - & - & - & - & 0.75 & 0.13 & 0.50 & 0.33 & 1.00 \\
\hline & 11 & 3.7 & - & - & - & - & - & - & 0.50 & 0.17 & 0.25 & - & 0.10 & 0.17 & - \\
\hline & 12 & 3.1 & - & - & - & - & - & - & - & 0.17 & - & - & - & 0.17 & - \\
\hline & 13 & 3.0 & - & - & - & - & - & - & - & - & - & - & - & - & 1.00 \\
\hline & 14 & 2.9 & 0.14 & - & - & - & 0.10 & - & 1.00 & 1.00 & - & 0.80 & 0.75 & 0.86 & 0.50 \\
\hline & 15 & 2.7 & 0.43 & 1.00 & 0.60 & 0.14 & - & - & 0.38 & 0.17 & 0.38 & 0.40 & 0.25 & 0.29 & - \\
\hline & 16 & 2.5 & 0.86 & 1.00 & 0.60 & 1.00 & 1.00 & 1.00 & 0.25 & - & 0.75 & 0.40 & 0.25 & 0.29 & 0.50 \\
\hline \multicolumn{16}{|c|}{ Probability of band } \\
\hline \multirow{2}{*}{\multicolumn{2}{|c|}{$\begin{array}{l}\text { Sharing } \\
\text { Present in the }\end{array}$}} & $x$ & 0.78 & 0.73 & 0.92 & 0.70 & 0.80 & 1.00 & 0.72 & 0.61 & 0.64 & 0.71 & 0.60 & 0.59 & 0.92 \\
\hline & heterozygous state & $h$ & 0.38 & 0.32 & 0.29 & 0.37 & 0.25 & 0.00 & 0.46 & 0.52 & 0.64 & 0.55 & 0.68 & 0.69 & 0.22 \\
\hline
\end{tabular}

*Localities as in Fig. 1 and Table 1.

Fragment sizes are measured in kilobases.

of the populations. The distribution of the common fragments varied in frequency among species. Fragment 2 was fixed in the species $2 n=52$ and $2 n=54$, and its frequency was high in most of the $2 n=60$ populations. It appeared in population 9 (Afiq) but was totally absent in population 7 and 8 (Kabri and Zippori), of $2 n=58$. Populations 7 and 8 harboured another fragment, no. 5 , probably allelic to fragment 2 , which appeared in every tested individual, and in a lower frequency in population 9. Thus, fragment 5 is species-specific to $2 n=58$. Fragment 3 may also be allelic to these two fragments ( 2 and 5 ); this fragment only appeared in population 9 of $2 n=58$ and in the main population of $2 n=60$. Fragment 11 (and less so, fragment 10) may distinguish the southern $(2 n=58$ and 60$)$ from the northern $(2 n=52$ and 54$)$ species.

Deciphering genes and allelic fragments in this system was complex, more than in the BamHI polymorphism. However, the number of bands per individual ranged from 3 to 5 , suggesting the existence of a few (probably 3 ) multiallelic genes (possible allelism of fragments $2,3,5$ ).
The second probable gene represented by fragment 8 was nearly monomorphic in $2 n=52$ and 54 . However, in the other two species, its frequency was lower, and fragments 11 in $2 n=58$ and fragment 10 of $2 n=60$ might possibly be allelic to it. This classification is problematic owing to the complete absence of fragment 11 'homozygotes', as well as a deficiency in fragment 10 'homozygotes'. Further study on a larger sample size is required to define the exact genetics of the multiband patterns of EcoRI polymorphism in Spalax.

The desert isolate population 13 (Sede Boqer) of $2 n=60$ exhibited a very interesting pattern. An additional new fragment $-13(3.0 \mathrm{~kb})$, appeared in the two tested individuals, suggesting a high frequency (or fixation of an additional fragment) in that population.

\section{Taq/polymorphism}

The per-homologous sequence polymorphism yielded many bands, as expected from the digestion of genomic DNA, with a four-base recognition endonuclease. 
Although most of the polymorphic fragments were unscorable on a population level, it seemed that there were two major different patterns. One represented the species $2 n=52,54$ and population 9 (Afiq) of $2 n=58$, and the other represented the other two populations of $2 n=58$ and all of the $2 n=60$ populations (Fig. $2 \mathrm{c}$ ). Once again, in this analysis, population 9 (Afiq) of $2 n=58$, displayed a pattern entirely different from the other populations of its species.

\section{Discussion}

\section{Number of genes/homologies}

The hybridization of the Drosophila per locus probe to genomic DNA detected different numbers of homologies in different unrelated taxa, such as the chicken, mouse, and man (Shin et al., 1985). Three different per RNA transcripts, generated by alternative splicing events of the per gene, differing in only about 10 per cent of their sequences, were found in Drosophila (Citri et al., 1987). In mammalian cells a repeating Ser-Gly sequence has been found in the proteoglycans: heparin sulfate (Robinson et al., 1978), dermatan sulfate (Chopra et al., 1985), chondritin sulfate (Bourdon et al., 1985; Miller et al., 1988) and in bovine cartilage (Oldberg et al., 1987).

The results of the present study indicate the existence of multiple DNA homologies in the four species of subterranean mammals of the Spalax ehrenbergi superspecies, similar to those of the mouse pattern (Shin et al., 1985). The probe used is characterized by the presence of tandem repetitions of short motifs (ACNGGN and TCAGGC), and was shown to allow the detection of DNA fingerprints in men, dogs, horses and pigs (Georges et al., 1987, 1988). The determination of the genetic basis of the different fragments described proved to be complex owing to the high level of polymorphism, the low frequency of some fragments, and the difficulty in establishing allelism. Nevertheless it seems that the probe detected a multigene family with more than 10 different homologies. Only three to four of them showed a stronger homology. It was possible to assign some of the bands that showed strong hybridization to specific loci, unlike DNA fingerprints. Moreover, the high stringency conditions used in hybridization and in washing the filters (much higher than those conducted by Georges et al., 1987, 1988), suggest very strong homologies between Spalax DNA and the mouse per-homologous sequence. One or more of these loci may code for proteoglycan(s) which may be involved in biological rhythmicity. This speculation, however, needs further critical testing.

\section{The level of polymorphism}

The level of polymorphism detected by hybridizing Spalax DNA with the mouse per-homologous sequence was very high, presumably with many alleles per locus. However, the variation within the population is much lower than that described by Jeffreys et al. (1985) for DNA fingerprints in human populations, or by Georges et al. (1988) for DNA fingerprints of perhomologous sequences of horses, chickens and fish. Many populations of Spalax are totally monomorphic (within populations), so that the mean probability that a fragment present in one individual is also present in another of the same population is $x=1.0$ (Tables 2 and 4). Another well known minisatellite probes (Jeffreys - 33.15) shows DNA fingerprinting in the most monomorphic populations of Spalax, with fragment-sharing among individuals of the same population at only 26 per cent (E. Nevo et al., in preparation).

Polymorphism was found in the three tested restriction enzymes, in all loci detected. Such a high level of polymorphism and a high number of alleles per locus (within the superspecies) are very interesting in view of the fact that subterranean mammals are generally characterized by a low level of protein polymorphism as compared with above-ground mammals (Nevo, 1978; Nevo et al., 1984; Nevo et al., 1990). A low level of DNA polymorphism and a low number of alleles were found in the RFLPs of haptoglobin (Nevo et al., 1989), where only one out of six restriction enzymes detect polymorphism, with a maximum of three alleles per locus. Moreover in the RFLPs of the myosin heavy chain, a maximum of two alleles per locus (per restriction enzyme) was detectable (R. Ben-Shlomo \& E. Nevo, in preparation). A high number of alleles per locus was found only in the RFLPs of the class II major histocompatibility complex, Mhc (Ben-Shlomo et al., 1988). Likewise, a high number of different haplotypes was found in mtDNA (E. Nevo et al., 1993).

At least one of the mutations that caused the polymorphism described in this study is located inside the probe region. As shown in Fig. 3, BamHI restriction enzyme divided the gene into fragment 1 and either fragment 3 or 7 . It is interesting that the recognition sequence of BamHI is GGATCC, which can translate into Gly-Ser amino acids. A poly-(Ser-Gly) acceptor site has been verified directly in the instance of the heparin sulfate proteoglycan (Robinson et al., 1978). Although the probe contained the Thr-Gly and the Ser-Gly encoding minisatellites could show homology with non-transcribed regions of the DNA, it is possible that the mutation occurred inside the acceptor site of the proteoglycan. It is reasonable that at least some of the other mutations also occurred inside the gene or in 
its near vicinity, especially those mutations that yielded the smaller fragments.

In S. ehrenbergi, the per-homologous sequence polymorphism increased in the following order: $54<52<58<60$; chromosomal species $2 n=54$ and $2 n=52$ were only slightly polymorphic. By contrast, $2 n=58$ was highly polymorphic and $2 n=60$ was even more so. These results concur with previous analyses of genetic diversity based on allozymes, in many unrelated species, which increase southwards with increasing aridity and unpredictability (Nevo, 1983; Nevo \& Beiles, 1988, 1989). The geographical variation of the per-homologous sequence polymorphism may indicate the underlying evolutionary forces molding it. If indeed the per-homologous sequence is related to behavioural factors associated with rhythmicity, then controlling rhythmicity in a climatically unpredictable region may be more complex, and may select for a higher level in the fine tuning of the regulatory polymorphic signals.

\section{Polymorphisms in isolated populations}

The Sede Boqer desert isolate (population 13) of $2 n=60$ exhibits a very interesting pattern. The Sede Boqer population is isolated by $\sim 40 \mathrm{~km}$ of harsh desert from the main range of $2 n=60$. This isolation may have persisted off and on during at least part of the last 10,000 years (Nevo, 1989). The current population size is very small: $\sim 100$ individuals.

The effect of the population size reduction (bottleneck effect) on average heterozygosity is expected to last for hundreds of thousands of years after the recovery of the population size (Nei et al., 1975). Likewise, it has been suggested that while allele numbers showed significant excesses when the population rapidly expanded from the homoallelic state, population size construction caused allelic deficiencies (Maruyama \& Fuerst, 1985). These neutral considerations suggest that in the Sede Boqer isolate of Spalax, where the bottleneck effect predominated for many generations with no population recovery, the level of variability would be extremely low. The opposite pattern is displayed in the Sede Boqer isolate, which harbours a substantial per-homologous sequence polymorphism.

An additional unique EcoRI fragment of $3.0 \mathrm{~kb}$ (no. 13) appeared only in this population. Although its frequency (100 per cent) may change because only two individuals were tested in this system, it should still be quite high. The existence of an allele of a gene that is unique to an isolated population is rare. We have previously found such a phenomenon in RFLPs of an unidentified muscle protein (R. Ben-Shlomo \& E. Nevo, unpublished data).

Genetic variability in this isolated population has been found in some allozymes, mtDNA, and chromosomal polymorphisms (Nevo, 1989); Mhc (BenShlomo et al., 1988), and in the myosin heavy chain ( $R$. Ben-Shlomo \& E. Nevo, in preparation). The relatively high level of genetic variation may contribute to successful speciation (Barton \& Charlesworth, 1984; Carson and Templeton, 1984; Nevo, 1989) of the desert isolate. A unique variation in a locus that might be connected to the courtship calls, hence to reproductive isolation, may support successful speciation.

Population 9 (Afiq) of $2 n=58$ also revealed interesting attributes. Afiq is a marginal population that is located in the southern Golan Heights (Fig. 1), south of the hybrid zone with $2 n=54$, and only $10 \mathrm{~km}$ from population 6 (El-Al, $2 n=54)$. Geographically, this population is an isolated relic of $2 n=58$, surrounded by the Yarmouk river to the south-east, and by the Sea of Galilee and the Jordan river to the west.

The results of the present study place population 9 in an intermediate position concerning its genetic differentiation. In both EcoRI and BamHI polymorphisms, this population exhibited a mixture of all the species, although a low level of the $2 n=58$ specific fragment was found. It seems that the Afiq population (9) reflects its origin from the $2 n=58$ species, as well as some alleles which indicate xeric ecological correlates that appear in the species $2 n=54$ and $2 n=60$.

Divergence between population 9 (Afiq) of $2 n=58$ and conspecific populations 7 and 8 has been seen in other genetic systems, such as the myosin heavy chain (R. Ben-Shlomo and E. Nevo, in preparation), rDNA spacer polymorphism (Suzuki et al., 1987) and mtDNA (E. Nevo et al., 1993). Notably, this population is very polymorphic, more than the other two populations of $2 n=58$. The population is much more polymorphic than the nearby population $6(\mathrm{El}-\mathrm{Al})$ of $2 n=54$, which was monomorphic in all the tested endonucleases. The high level of polymorphism of the Afiq population is reminiscent of the high level of polymorphism of the species $2 n=60$, suggesting, intraspecifically, a positive correlation between the level of polymorphism and the climatic unpredictability within $2 n=58$.

\section{Fragment differences between and within chromosomal species}

Fragment variation allows us to distinguish between chromosomal species (Table 2 and Fig. 2). There are three main patterns. The first characterizes the species $2 n=52$ and 54 , the second represents population 7 and 8 of $2 n=58$, and the third that of $2 n=60$. Popula- 
tion 9 of $2 n=58$ shows an intermediate pattern which is dependent on the restriction enzyme and gene.

The most distinct species demarcation is the one expressed in fragment 5 of EcoRI. This diagnostic species-specific fragment appeared only in the three populations of $2 n=58$ (Table 2). This is the first case that such an alternative fixation of alleles was found within the species of the $S$. ehrenbergi complex in Israel. Similarly, 93 per cent of the haplotypes of mtDNA are species-specific (E. Nevo et al., 1993.) The uniqueness of $2 n=58$ is expressed in other cases, such as the combination of $8-10$ or fragment 4 homozygotes of EcoRI, although it does not display complete discrimination. Other fragments that were specific to the species $2 n=58$ and 60 are fragment 3 of BamHI and fragment 3 of EcoRI.

\section{Does the per-homologous sequence code for rhythmicity in Spalax?}

The best described clock gene is the per gene of Drosophila melanogaster (Hall, 1990). The similarities between the properties of the per gene of Drosophila and another identified clock gene, the frequency (frq) gene of Neurospora, suggest that per and frq might code for similar proteins (Feldman, 1988). DNA sequence comparisons between frq and per (McClung et al., 1989), suggest the possibility of a common element in the time mechanisms of these two organisms. The chloroplast genome of Acetabularia, which is assumed to encode the p230 clock protein, shares homology with the per locus of Drosophila (Li-Weber et al., 1987). The specific per protein antibody (anti- $p$ er) labelled putative circadian pacemaker neurons and fibres in the eyes of two marine gastropods, Aplysia and Bulla (Siwicki et al., 1989). Genetic studies of factors underlying circadian pacemaking are beginning to indicate that time mechanisms may also be ancient entities that have been highly conserved in evolution (Hall, 1990).

The biochemistry and physiology of proteins such as those encoded by the period genes of Drosophila may be understood by characterizing and manipulating per protein relatives in other organisms, in which circadian pacemakers have been identified at tissue locations and are accessible in cellular terms (Hall, 1990). A different approach to the question of the similarities between the per gene product and rhythmicity in other organisms could be attempted by correlating variability in the perhomologous sequence with different rhythmicity parameters. Although there is no evidence that the RFLPs have anything to do with time-dependent genes, positive significant correlations can provide another strategy and direction for further investigation.
Such a correlation was found in the Spalax complex among different fragments of the per-homologous sequence found in this research, and the mean number of the apparent harmonics (or additional frequencies) parameter of the courtship calls (Nevo et al., 1987; E. Nevo et al., personal communication). A highly significant correlation was found between the low number of harmonics and fragments $7(r=-0.90, P<0.01)$ and 1 of $\operatorname{BamHI}(r=-0.91, P<0.001)$, and fragment 2 of $\operatorname{EcoRI}(r=-0.84, P<0.01)$, as well as between the high number of harmonics and fragments 3 and 4 of BamHI $\quad(r=+0.84, \quad P<0.01$ and $r=+0.067$, $P<0.05$, respectively). This correlation suggests the possibility of gene(s) (homology) that are responsible for courtship call (the apparent number of harmonics) parameters. Only further research can shed light on the significance of this correlation. If the correlation is substantiated, and if female discrimination is affected by this parameter, then the above-mentioned correlation may indicate that the per-homologous sequence is associated with vocalization. As courtship calls are associated with mate selection, they do contribute to the essential behaviour mechanisms involved in the critical aspects of reproductive isolation in the actively speciating Spalax complex of species in Israel. In this case, per variation may affect speciation.

\section{Acknowledgements}

This study was supported by the Israel Discount Bank Chair of Evolutionary Biology (EN) and the AncellTeicher Research Foundation for Genetics and Molecular Evolution, established by Florence and Theodore Baumritter of New York (EN); and the Markey Charitable Fund (HS).

\section{References}

BARTON, N. H. AND CHARLESWORTH, B. 1984. Genetic revolutions, founder effects, and speciation. Ann. Rev. Ecol. Syst., 15, 133-164.

BEN-SHLOMO, R., FIGUEROA, F., KLEIN, J. AND NEVO, E. 1988. Mhc class II DNA polymorphisms within and between chromosomal species of the Spalax ehrenbergi superspecies in Israel. Genetics, 119, 141-149.

BOURDON, M. A., OLDBERG, A., PIERSCHBACHER, M. AND RUOSLAHT, E. 1985. Molecular cloning and sequence analysis of a chondroitin sulfate proteoglycan cDNA. Proc. Natl. Acad. Sci., U.S.A., 82, 1321-1325.

CARSON, H. L. AND TEMPLETON, A. R. 1984. Genetic revolutions in relation to speciation: The founding of new populations. Ann. Rev. Ecol. Syst., 15, 97-131.

CITRI, Y., COLOT, H. V., JACQUIER, A. C., YU, Q., HALL, J. C., BALTIMORE, D. AND ROSBASH, M. 1987. A family of unusually spliced biologically active transcripts encoded by a Drosophila clock 
gene. Nature, 326, 42-47.

CHOPRA, R., PEARSON, C. H., PRINGLE, G. A., FACKRE, D. S. AND SCOTT, P. G. 1985. Dermatan sulphate is located on serine-4 of bovine skin proteodermatan sulphate. Biochem. J., 232, 277-279.

EDMUNDS, L. N. JR., 1988. Cellular and Molecular Bases of Biological Clock: Models and Mechanisms for Circadian Timekeeping. Springer-Verlag, New York.

FEINBERG, A. P. AND VOGLESTEIN, B. 1984. A technique for radiolabeling DNA restriction endonuclease fragments to high specific activity. Anal. Biochem., 137, 266-267.

FELDMAN, J. F. 1982. Genetic approaches to circadian clocks. Ann. Rev. Plant Physiol., 33, 583-608.

FELDMAN, J. F. 1988. Genetic of circadian clocks. Bot. Acta, 101, 128-132.

GEORGES, M., COCHAUX, P., LEQUARRE, A. S., YOUNG, M. W. AND VASSART, G. 1987. DNA fingerprint in man using a mouse probe related to part of the Drosophila 'Per' gene. $\mathrm{Nucl}$. Acids Res., 15, 7193.

GEORGES, M., LEQUARRE, A.-S., CASTELLI, M., HANSET, R. AND VASSART, G. 1988. DNA fingerprinting in domestic animals using four different minisatellite probes. Cytogenet. Cell Genet., 47, 127-131.

HAIM, A., HETH, G., PRATT, H. AND NEVO, E. 1983. Photoperiodic effects on thermoregulation in a 'blind' subterranean mammal. J. Exp. Biol., 107, 59-64.

HALL, J. C. 1984. Complex brain and behavioral functions disrupted by mutations in Drosophila. Dev. Genet., 4, 355-378.

HALL, J. C. 1990. Genetics of circadian rhythms. Ann. Rev. Genet., 24, 659-697.

Holland, 1. B. 1983. Basic Cloning Techniques: Course manual. University of Leicester, Leicester, U.K.

JACKSON, F. R., BARGIELLO, T. A., YUN, S. H. AND YOUNG, M. W. 1986. Product of per locus of Drosophila shares homology with proteoglycans. Nature, 320, 185-188.

JEFFREYS, A. J., WILSON, v. AND THEIN, S. L. 1985. Individual-specific 'fingerprints' of human DNA. Nature, 316, 76-79.

KONOPKA, R. J. AND BENZER, s. 1971. Clock mutants of Drosophila melanogaster. Proc. Natl. Acad. Sci., U.S.A., 68, 2112-2116.

KYRIACOU, C. P. AND HALL, J. C. 1980. Circadian rhythm mutations in Drosophila melanogaster affect short-term fluctuations in the male's courtship song. Proc. Natl. Acad. Sci., U.S.A., 77, 6729-6733.

LI-WEBER, M., DE GROOT, E. J. AND SCHWEIGER, H.-G. 1987. Sequence homology to the Drosophila per locus in higher plant nuclear DNA and in Acetabularia chloroplast DNA. Mol. Gen. Genet., 209, 1-7.

MCCLUNG, C. R., FOX, B. A. AND DUNLAP, J. C. 1989. The Neurospora clock gene frequency shares a sequence element with the Drosophila clock gene period. Nature, 339, 558-562.

MARUYAMA, T. AND FUERST, P. A. 1985. Population bottlenecks and nonequilibrium models in population genetics. II. Number of alleles in a small population that was formed by a recent bottleneck. Genetics, 111, 675-689.

MILLER, J., HATCH, J. A., SIMONIS, S. AND CULLEN, S. E. 1988. Identification of the glycosaminoglycan-attachment site of mouse invariant-chain proteoglycan core protein by site- directed mutagenesis. Proc. Natl. Acad. Sci., U.S.A., 85, 1359-1363.

NEI, M., MARUYAMA, T. AND CHAKRABORTY, R, 1975. The bottleneck effect and genetic variability in populations. Evolution, 29, 1-10.

NEvo, E. 1978. Genetic variation in natural populations: patterns and theory. Theor. Pop. Biol., 13, 121-177.

NEVO, E. 1983. Population genetics and ecology: the interface. In: Bendall, D. S. (ed.) Evolution from Molecules to Man, Cambridge University Press, Cambridge, pp. 287-321.

NEVO, E. 1989. Modes of speciation: the nature and role of peripheral isolates in the origin of species. In: Giddings, L. V., Kaneshiro, K. Y. and Anderson, W. W. (eds) Genetics, Speciation and the Founder Principle, Oxford University Press, Oxford, pp. 205-236.

NEVO, E. 1991. Evolution of vocal and vibrational communications in blind, photoperiod-perceptive, subterranean mole rats: Structure and Function. In: Le Berre, M. and Le Guelte, L. (eds) Le Rongeur et L'Espace, Edition R. Chabaud, Paris, pp. 15-34.

NEVO, E. AND BEILES, A. 1988. Genetic parallelism of protein polymorphism in nature: ecological test of the neutral theory of molecular evolution. Biol. J. Linn. Soc., 35, 229-245.

NEVO, E. AND BEILES, A. 1989. Genetic diversity in the desert: patterns and testable hypotheses. J. Arid Environ., 17, 241-244.

NEVO, E., BEILES, A. AND BEN-SHLOMO, R. 1984. The evolutionary significance of genetic diversity: ecological, demographic and life history correlates. In: Mani, G. S. (ed.) Lecture Notes in Biomathematics (Evolutionary Dynamics of Genetic Diversity), Springer-Verlag, Berlin, pp. 13-213.

NEVO, E., BEN-SHLOMO, R. AND MAEDA, N. 1989. Haptoglobin DNA polymorphism in subterranean mole rats of the $S p a-$ lax ehrenbergi superspecies in Israel. Heredity, 62, 85-90.

NEVO, E., FILIPPUICCI, M. G. AND BEILES, A. 1990. Genetic diversity and its ecology correlates in nature: comparisons between subterranean, fossorial and aboveground, small mammals. In: Nevo, E. and Reig, O. A. (eds) Evolution of Subterranean Mammals at the Organismal and Molecular Levels, Alan R. Liss, New York, pp. 347-366.

NEVO, E., GUTTMAN, R., HABER, M. AND EREZ, E. 1982. Activity patterns of evolving mole rats. J. Mamm., 63, 453-463.

NEVO, E., HETH, G., BEILES, A. AND FRANKENBERG, E. 1987. Geographic dialects in blind mole rats: role of vocal communication in active speciation. Proc. Natl. Acad. Sci., U.S.A., 84, 3312-3315.

NEVO, E., HONEYCUTT, R. L., YONEKAWA, H., NELSON, K. AND HANZAWA, N. 1993. Mitochondrial DNA polymorphisms in subterranean mole rats of the Spalax ehrenbergi superspecies in Israel and its peripheral isolates. Mol. Biol. Evol. (in press).

OLDBERG, A., ANTONSSON, P. AND HEINEGARD, D. 1987. The partial amino acid sequence of bovine cartilage proteoglycan deduced from a cDNA clone contains numerous Ser-Gly sequences arranged in homologous repeats. Biochem. J., 243, 255-259.

PEVET, P., HeTh, G., HaIM, A. AND NeVo, E. 1984. Photoperiod perception in the blind mole rat (Spalax ehrenbergi, Nehr- 
ing): involvement of the Harderian gland, atrophied eyes and melatonin. J. Exp. Zool., 232, 41-50.

RALPH, M. R. AND MENAKER, M. 1988. A mutation of the circadian system in Golden Hamsters. Science, 241, 1225-1227.

REDDY, P., JACQUIER, A. C., ABOVICH, N., PETERSEN, G. AND ROSBACH, M. 1986. The period clock locus of $D$. melanogaster codes for a proteoglycan. Cell, 46, 53-61.

REPPERT, S. M., SCHWARTZ, W. J. AND UHL, G. R. 1987. Arginine vasopressin: a novel peptide in cerebrospinal fluid. Trends Neurosci, 10, 76-80.

ROBINSON, H. C., HORNER, A. A., OOK, M., OGREN, S. AND LINDAHL, U. 1978. A proteoglycan form of heparin and its degradation to single-chain molecules. J. Biol. Chem., 253, 6687-6693.

SCHWARTZ, W. J. AND ZIMMERMAN, P. 1990. Circadian timekeeping in BALB/c and C57BL/6 inbred mouse strains. $J$. Neurosci, 10, 3685-3694.
SIWICKI, K. K., STRACK, S., ROSBASH, M., HALL, J. C. AND JACKLET, J. W. 1989. An antibody to the Drosophila period protein recognizes circadian pacemaker neurons in Aplysia and Bulla. Neuron, 3, 51-58.

SHIN, H.-S. BARGIELLO, T. A., CLARK, B. T., JACKSON, F. R. AND YOUNG, M. w. 1985. An unusual coding sequence from a Drosophila clock gene is conserved in vertebrates. Nature, 317, 445-448.

SOUTHERN, E. M. 1975. Detection of specific sequences among DNA fragments separated by gel electrophoresis. J. Mol. Biol., 98, 503-517.

SUZUKI, H., MORIWAKI, K. AND NEVO, E. 1987. Ribosomal DNA (rDNA) spacer polymorphism in mole rats. Mol. Biol. Evol., 4, 602-610.

TAKAHASHI, J. S. AND ZATZ, M. 1982. Regulation of circadian rhythmicity. Science, 217, 1104-1111.

YU, Q., COLOT, H. V., KYRIACOU, C. P., HALL, J. C. AND ROSBACH, M. 1987. Behaviour modification by in vitro mutagenesis of a variable region within the period gene of Drosophila. Nature, 326, 765-769. 